Enas Yassen Shihab MSc, (Lec.)

Bakar Seddiq Mahmood MSc, (Asst. Lec.)

Ghada Younis Abdulrahman PhD. (Asst.Prof)

\section{The Antibacterial Effect of Magnetized Water on Oral Microorganisms}

\author{
Department of Dental Basic Sciences \\ College of Dentistry, University of Mosul \\ Northern Technical college
}

Department of Dental Basic Sciences

College of Dentistry, University of Mosul

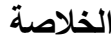

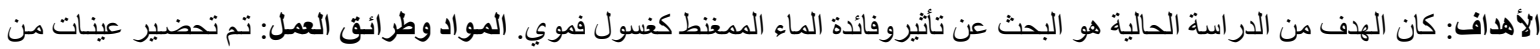

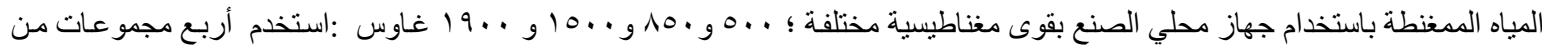

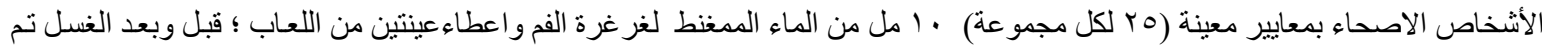

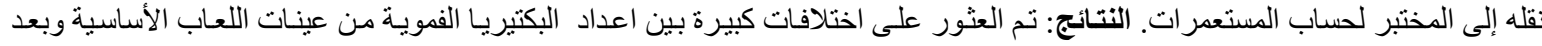

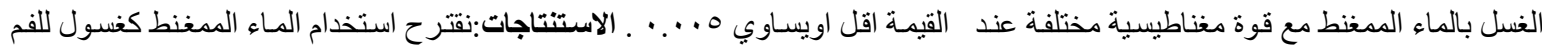 \\ باعتباره طاز جا ورخيصا ومتوفر اللوصول صحة صنة فموية جيدة.
}

\begin{abstract}
Aims: The purpose of this study was to investigate the effect of magnetized water as an oral irrigant. Materials and Methods: Samples of magnetized water were prepared using a locally made device at different magnetic strengths; 500, 850, 1500 and 1900 Gauss; four groups of healthy individuals with certain criteria ( 25 for each group) rinsed their mouth with $10 \mathrm{ml}$ of the magnetized water and two saliva samples; before and after irrigation were collected, transferred to the laboratory for colony counting. Results: significant differences were found between the $\mathrm{CFU} / \mathrm{ml}$ of oral bacteria from baseline saliva samples and after irrigating with magnetized water with different magnet strengths at $\mathrm{p} \leq 0.005$. Conclusion : As the good antibacterial, fresh, cheap, and available; the regular use of magnetized water was suggested as the irrigant solution for good oral hygiene.
\end{abstract}

Key words: Magnetized water, Antibacterial, Irrigant

Shihab EY., Mahmood BS., Abdulrahman Gh Y. The antibacterial effect of Magnetized water on oral microorganisms. Al-Rafidain Dent J. 2020 ;20 (2):257-264.

DOI: 10.33899/rden.2020.166473 @2020, College of Dentistry, University of Mosul

Received: 31/5/2020 Sent to Referees: 1/6/2020Ａccepted for Publication: 22/7/2020

This is an open access article under theCCBY4.0license (http://creativecommons.org/licenses/by/4.0/).

\section{INTRODUCTION}

Magnetic water is based on science that started to invade many areas of the worlds, some consider it a magic description that achieves many benefits at one time. In industry, it achieves a real fence of equipment and production lines against wear and tear and rapidly deteriorating salts. Magnetism is well known in the field of physics. Magnets prove to 
be a strong safeguard against illness and serve as a highly beneficial preventive device. When water passes through the magnetic field, it undergoes certain changes. The magnetic field alters the electrical characteristics of hydrogen ions as well as minerals ${ }^{(1)}$. It is also known to draw pain out from the body, reduces stiffness of joints and muscles, and removes a toothache immediately. When water passes through the magnetic field, it undergoes certain changes. The magnetic field alters the electrical characteristics of hydrogen ions as well as minerals. The bio-south magnets help in reducing scale buildup. The bio-north magnetic water is used in the treatment of various diseases. The bio-south magnetic field stimulates the system ${ }^{(2)}$

The force of magnetism influences the life of organisms. When a permanent magnet is kept in contact with water continuously for known time, the magnetic flux of magnet influences the water and becomes magnetized, also acquires magnetic properties. Best results are obtained if the water is used immediately after treatment (3). Its acceptability and longterm use as the mouth rinse by patients is associated with these side effects, more appropriate alternatives, especially for children, is needed. Thus, there has been a focus to find another natural alternative and cheap agents. These natural products have major advantages, that no side effect has been reported after their use $^{(4)}$
Scientists investigated the biological effect of a magnetic field by exposure three species of bacteria: Streptococcus mutans, Staphylococcus aureus, and Escherichia coli to ferrite magnets, and the results showed that the ferrite magnet field caused strength- dependent inhibition in growth rate and maximum decrease of bacterial numbers for Staph aureus and Strept.mutans especially under anaerobic conditions were obtained but was not inhibited under aerobic conditions ${ }^{(5)}$.Magnetic water is a modernistic technology using magnetic devices which make vigorous concentration of magnetic field through the tube wall to deal with water and contribute with its properties .Treating water with magnetic forces (AMT or anti-scale magnetic treatment) is a controversial way believed to reduce the hard water effects by passing water through a magnetic field, which is a non-chemical method for water softening (6). The feasibility of Multi Drug Resistant (MDR) P. aeruginosa resistance Colistin which formed biofilm before using Magnetic water and after, were studied and observed that Colistin resistant $P$. aeruginosa had lost the ability to form the biofilm ${ }^{(7)}$

The early studies conducted on the electromagnetism and their influence on organisms dates back on from the end of the nineteenth century, then concentrated on the following decades after the diffusion of telecommunication and global electrification. In contrast to the studies indicated above, the 
research that investigates the field effects on microorganisms is very limited. For better understanding, well-characterized model microorganisms, with genetic markers, were used in medical -health research ${ }^{(8)}$. Calculus formed on the tooth surfaces is analogous to the formation of lime and scale deposits in water pipes. Magnetized water devices significantly reduce the scale deposits in the industry; therefore, an oral irrigator with a magnetic water device may give a similar effect on the tooth calculus ${ }^{(9)}$. Since many types of researches have been done with the use of magnets in the medical field, its use in dentistry is still lacking.

\section{MATERIALS AND METHODS}

a- Magnetized Water sample preparation:

The tap water was magnetized by a locally made device at different magnetic strengths; where a Pyrex-type laboratory glass tube (12 $\mathrm{cm}$ in length and $13 \mathrm{~mm}$ in diameter) was taken and two magnetic pieces were installed on the outer diameter of the glass tube and it was of neodymium type. To prevent the tube from being broken and preserve the magnetic piece, the sides of this tube were covered with a locked casing designed for this as well ,perforating the middle of this cap to pass the sides of the glass tube through it and fix them by the handbag, and several devices were made with different magnetic strengths of 500,850, 1500, 1900 Gauss. The magnetic device was shown in (Figure 1).

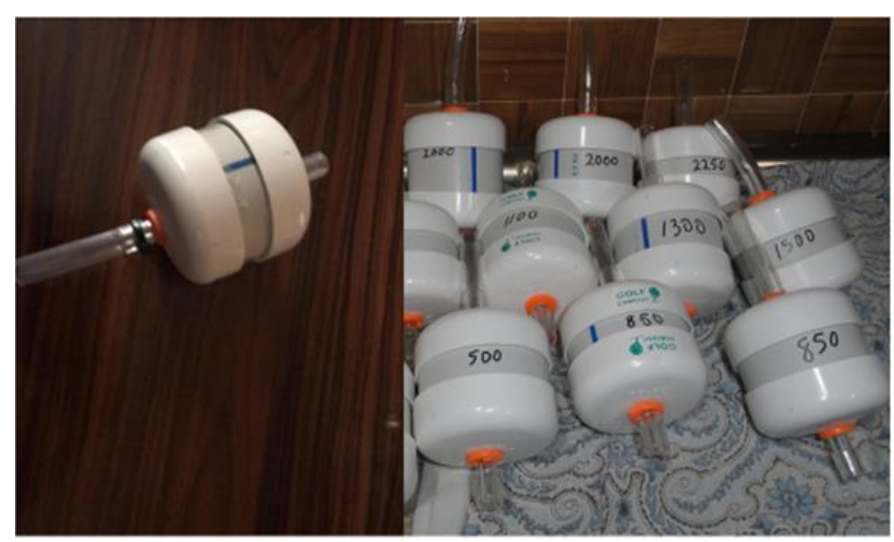

Figure (1): The local made magnetic device

\section{b-In Vivo study:}

Saliva samples collection:

One hundred healthy persons of both sexes were included in this study, their ages ranged from 12-60 years, with no history of systemic diseases, and none of them were receiving antimicrobial treatment at the time of the study. Those persons were divided into four groups according to the magnetic strength used:

Group I: 500 Gauss (25 persons)

Group II: 850 Gauss (25 persons)

Group III: 1500 Gauss (25 persons)

Group IV: 1900 Gauss (25 persons) 
They were instructed not to eat or brush their teeth and not to rinse their mouths by mouth rinses at the morning of the experiment. The baseline saliva samples were collected from all groups with sterile vials, after that they were instructed to rinse their mouths by 10 milliliters of magnetized water samples for one minute, and the saliva samples after rinsing were collected into sterile vials. All vials were transferred to the laboratory immediately.

\section{c-Microbiological method:}

One milliliter of each sample (vial) was diluted decimally and then one milliliter of each dilution was cultured on Brain Heart Infusion agar plates (three replicates for each dilution), all petri dishes were incubated in 37 $\mathrm{C}^{0}$ for 24-48 hours, and the number of colonies was counted as $\mathrm{CFU} / \mathrm{ml}{ }^{(10)}$.
The mean of the three replicates of the CFU/ml for saliva samples before and after rinsing with magnetized water was analyzed and compared using the SPSS program V.25 . The means for groups between homogeneous subsets were displayed, compared by Wilcoxon Signed Rank Test. The differences were considered significant at $\mathrm{p} \leq 0.005$.

\section{RESULTS}

After incubation, the bacterial cultures resulted from the baseline saliva specimens and the saliva samples after irrigation with the different magnetized water samples of different strengths were counted with aid of an $8 \mathrm{X}$ glass magnifier and colony -forming units per one milliliter (CFU/ml) were calculated .Cultures of samples before (A) and after rinsing (B) were shown in (Figure 2).

\section{d-Statistical method:}

A

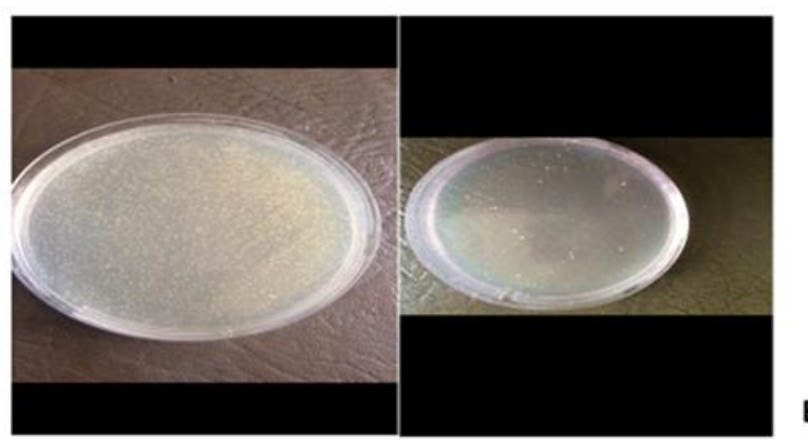

Figure (2): Effect of magnetic water with 500 Gauss magnet device on salivary bacterial count(A:befor use, B: after use)

The number of colonies decreased in the samples of saliva after irrigation with magnetized water with all strengths, especially with the 500,850 and 1900 Gauss, as shown in (Tables 1, 2) 
Table (1): ANOVA test explaining the significant difference between testing groups

\begin{tabular}{|c|c|c|c|c|c|}
\hline count & Sum of squares & df & Mean square & $\mathbf{F}$ & Sig. \\
\hline $\begin{array}{l}\text { Between groups } \\
\text { Within groups } \\
\text { Total }\end{array}$ & $\begin{array}{l}140900.235 \\
777462.160 \\
918362.392\end{array}$ & $\begin{array}{l}7 \\
192 \\
199\end{array}$ & $\begin{array}{l}20128.605 \\
4049.282\end{array}$ & 4,971 & .000 \\
\hline
\end{tabular}

Table (2): Duncan's table of the effect of magnetic strengths on number of colonies in saliva

$(1,2,3 \ldots$ different subsets with significance*)

\begin{tabular}{|l|l|l|l|||}
\hline treatment & No. & \multicolumn{2}{|l|}{ Subbsets for alpha $=0.005$} \\
\hline 500 G-before & 25 & 2 & \\
\hline 500 G-after & 25 & $1^{*}$ & \\
\hline 850 G-before & 25 & $2 *$ & 3 \\
\hline 850 G-after & 25 & 2 & \\
\hline 1500 G-before & 25 & 2 & \\
\hline 1500 G-after & 25 & & \\
\hline 1900 G-before & 25 & $2 *$ & 3 \\
\hline 1900 G-after & 25 & 25 & \\
\hline
\end{tabular}

Table number one show us the significant effect of the magnetized water on the CFU/ml calculations after statistical analysis, especially the 500,1500,and 1900 Gauss magnetic strengths, also the effect is very clear in the histogram shown in (Figure 3 )

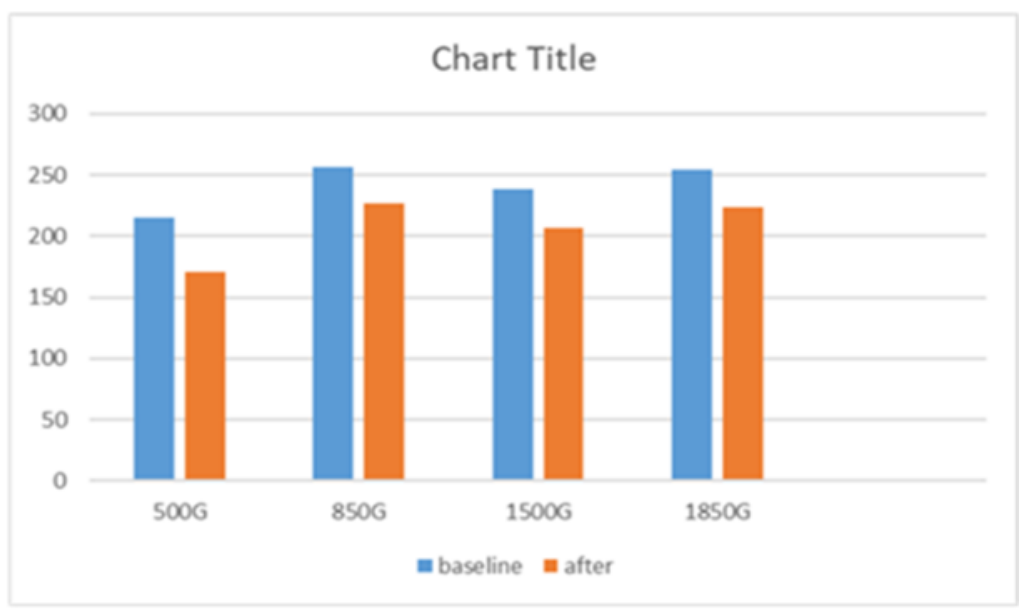

Figure (3):The effect of different magnetic strength on microbial counts Before treatment After treatment 


\section{DISCUSSION}

Human body is composed of over $70 \%$ water. Circulation, absorption, digestion, and excretion depend on water that is required for blood, lymph, skin, and muscles. The $\mathrm{pH}$ of the human body is more acidic when we are sick. Magnetized water is alkaline, which raises our body $\mathrm{pH}$, which allows the body to remove the toxins. Bio-magnetized water is energy building, activating, and detoxifying ${ }^{(2,11)}$

The relationship between magnetic power and water, what we understand from the old literature is that water $-\mathrm{H}_{2} \mathrm{O}$, with its bonds of hydrogen is related to each other, and these linkages may be bilateral or multiple. This may reach a large number of bonds, if we place water molecules within a magnetic field, these bonds between either atoms change or dissolve, and the dissociation absorb energy and reduces the water atoms union level, raising the ability of electrolysis and affecting the crystal dissolution.

Simply, water treatment with magnetic fields brings back the balance and natural energy that nature intended. Magnetized water has hydroxyl $(\mathrm{OH}-)$ ions much more than tap water, which makes it alkaline and reduces the acidity. Tap water has a $\mathrm{pH}$ of about 7. While magnetized water is alkaline, its $\mathrm{pH}$ is as high as 9.2. One benefit of the magnetic force is reducing the surface tension of the water, making it feel softer, wetter, thinner, and more absorbable, and is able to penetrate cell walls carrying the nutrients ${ }^{(9) .}$ Controversy regarding the impact effects of the magnetic field on water results from the physical structure of liquid water. Hydrogen micro clusters are formed when water is magnetized, these clusters react with oxygen molecules forming sodium hydroxide $(\mathrm{NaOH})$, the water's $\mathrm{pH}$ is increased making it extra alkaline ${ }^{(13)}$

The oral irrigator using magnetized water could be a beneficial adjunct to prevent the accumulation of calculus in periodontal patients, but it has a minimal effect on plaque reduction. Also, there is clinical improvement in the gingival index, but no statistical

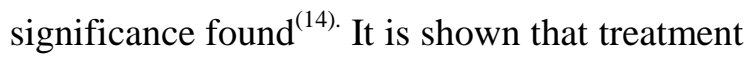
with magnetized water highly reduced the calculus accompanied or coexisted with caries (14) Magnetized water prevents the bonding process between the plaque and the teeth by "magneto-hydro-dynamics", which prevents naturally occurring mineral deposits in fluids ${ }^{(4)}$

\section{CONCLUSIONS}

It is important to develop the knowledge of treatment with magnetized water, the target where we can predict the effects of magnetic treatment reliably and proven to be economically attractive.

\section{Acknowledgment:}

The authors are very grateful to the university of Mosul, College of Dentistry for 
providing facilities, which helped to improve the quality of this work .

\section{REFERENCES}

1. Gupta N \& Bhat M.(2011). Comparative Evaluation of 0.2 percent Chlorhexidine and Magnetized Water as a Mouth Rinse on Streptococcus mutans in Children. Int J C Pediatric Dentistry ;4(3):190-194.

2. Goyal AK, Rathore AS, Garg M, Mathur R, Sharma M, Khairwa A. (2017)Effect of Magnetized Water Mouth rinse on Streptococcus mutans in Plaque and Saliva in Children: An in vivo Study. Int J C Pediatric Dentistry ;10(4):335-339.

3. Hari AR. (2008). Water-a miracle therapy magnetized water. Pustak Mahal 2008;10(1):78-79.

4. Lone N, Sidiq M, Khan M, Shah AF, Yousuf A.(2016 )Short Term Effects of Magnetized Water and Chlorhexidine on Plaque Accumulation and Gingival Inflammation- A Randomized Clinical Study. Annals Int Medical and Dental Research, Vol (2), Issue (3) pp91-94

5. Kohno M, Yamazaki M, Kimura I, Wada M. (2000). Effect of static magnetic fields on bacteria: Streptococcus mutans, Staphylococcus aureus, and Escherichia coli. Pathophysiology ;7(2):143-148.
6. Loraine A. Huchler, P.E .(2002).Nonchemical Water Treatment Systems: Histories, Principles and Literature Review., Mar-Tech Systems, Inc., Lawrence ville, NJ. International Water Conference, Pittsburgh, PA, 22 October 2002

7. Mahdia KH, Sabab HS , Mohammede NR\& Jawad MM.( 2017). The bactericidal activity of Magnetic water on Multi Drug Resistance [ MDR] Pseudomonas aeruginosa Resistance Colistin from clinical and environmental sources and effect on Biofilm . The 1st International Conference on Sciences and Arts (ICMSA 2017 (

8. Beretta G, Mastorgio AF , Pedrali L, Saponaro S \& Sezenna E.(2019). The effects of electric, magnetic and electromagnetic fields on microorganisms in the perspective of bioremediation Rev Env Sci Biotechnol (2019) 18:29-75

9. Watt DL, Rosenfelder C, Sutton CD.(1993) . The effect of oral irrigation with a magnetic water treatment device on plaque and calculus. J Clin Periodontol. 1993 May;20(5):314-7.

10. Hunt $K$, Vacelet $M$, and Jordan K.(2017).Determination of Listeria monocytogenes numbers at less than 10 cfu/g. Irish J Agr and Food 
Research10, Volume 56: Issue 1. DOI:https://doi.org/10.1515/ijafr-2017-

0004 Published online: 09 Jun 2017

11. Forsythe J. (2007). Themiracle of Biomagnetic water. Available from: https://ezinearticles.com/

12. Kamel FH, Dr. Rasheed TK, Hassan PA \& Qader SS .(2016)Effect of Magnetic Water on Immune Response in Rabbit against Pathogenic Bacteria. Eng. \& Tech. Journal, Vol. 34, Part (B), No. 3: 425-433 .
13. Johnson KE1, Sanders JJ, Gellin RG, Palesch YY.(1998)The effectiveness of a magnetized water oral irrigator (Hydro Floss) on plaque, calculus and gingival health. J Clin Periodontol. 1998 Apr;25(4):316-21.

14. Ebrahim SA \& Azab AE.(2017). Biological Effects of Magnetic Water on Human and Animals Biomedical Sciences 2017; 3(4): 78-85 . . 